\title{
Zinc deficiency primes the lung for ventilator-induced injury
}

\author{
Francis Boudreault, ${ }^{1}$ Miguel Pinilla-Vera, ${ }^{2}$ Joshua A. Englert, ${ }^{3}$ Alvin T. Kho, ${ }^{4}$ Colleen Isabelle, ${ }^{2}$ \\ Antonio J. Arciniegas, ${ }^{2}$ Diana Barragan-Bradford, ${ }^{2}$ Carolina Quintana, ${ }^{2}$ Diana Amador-Munoz, ${ }^{2}$ \\ Jiazhen Guan, ${ }^{2}$ Kyoung Moo Choi, ${ }^{5}$ MICU Registry, ${ }^{2}$ Lynette Sholl, ${ }^{6}$ Shelley Hurwitz, ${ }^{7}$ \\ Daniel J. Tschumperlin, ${ }^{5}$ and Rebecca M. Baron ${ }^{2}$ \\ 'Department of Environmental Health, Harvard School of Public Health, Boston, Massachusetts, USA. ${ }^{2}$ Pulmonary \\ and Critical Care Division, Department of Medicine, Brigham and Women's Hospital, Harvard Medical School, Boston, \\ Massachusetts, USA. 'Division of Pulmonary, Critical Care, and Sleep Medicine, The Ohio State Wexner Medical Center, \\ Columbus, Ohio, USA. ${ }^{4}$ Boston Children's Hospital Informatics Program, Boston, Massachusetts, USA. ${ }^{5}$ Department of \\ Physiology and Biomedical Engineering, Mayo Clinic, Rochester, Minnesota, USA. ${ }^{6}$ Department of Pathology and ${ }^{7}$ Center \\ for Clinical Investigation, Brigham and Women's Hospital, Harvard Medical School, Boston, Massachusetts, USA.
}

Mechanical ventilation is necessary to support patients with acute lung injury, but also exacerbates injury through mechanical stress-activated signaling pathways. We show that stretch applied to cultured human cells, and to mouse lungs in vivo, induces robust expression of metallothionein, a potent antioxidant and cytoprotective molecule critical for cellular zinc homeostasis. Furthermore, genetic deficiency of murine metallothionein genes exacerbated lung injury caused by high tidal volume mechanical ventilation, identifying an adaptive role for these genes in limiting lung injury. Stretch induction of metallothionein required zinc and the zinc-binding transcription factor MTF1. We further show that mouse dietary zinc deficiency potentiates ventilator-induced lung injury, and that plasma zinc levels are significantly reduced in human patients who go on to develop acute respiratory distress syndrome (ARDS) compared with healthy and non-ARDS intensive care unit (ICU) controls, as well as with other ICU patients without ARDS. Taken together, our findings identify a potentially novel adaptive response of the lung to stretch and a critical role for zinc in defining the lung's tolerance for mechanical ventilation. These results demonstrate that failure of stretch-adaptive responses play an important role in exacerbating mechanical ventilator-induced lung injury, and identify zinc and metallothionein as targets for lung-protective interventions in patients requiring mechanical ventilation.

Authorship note: F. Boudreault, M. Pinilla Vera, and J.A. Englert contributed equally to this work. D.J. Tschumperlin and R.M. Baron contributed equally to this work.

Conflict of interest: The authors have declared that no conflict of interest exists.

Submitted: January 13, 2016

Accepted: April 25, 2017

Published: June 2, 2017

Reference information:

JCI Insight. 2017;2(11):e86507.

https://doi.org/10.1172/jci.

insight.86507.

\section{Introduction}

Acute respiratory distress syndrome (ARDS) affects $\sim 200,000$ patients/year in the US, with 30\% mortality or higher (1-3). Mechanical ventilation (MV) is often lifesaving but can also exacerbate lung injury (4-6). While ventilator management is constantly being refined and low tidal volumes (Vt's) improve clinical outcomes (7-9), complications of MV remain a major clinical problem (10). Improved understanding of the factors that determine the lung's tolerance for stretch is needed to better define clinical risk and to design interventions that protect against and treat lung injury, with the ultimate goal of improving critical illness outcomes $(4,11)$.

MV of injured lungs causes high mechanical stress, even with modest inflation pressures, because of nonuniform gas distribution from alveolar collapse and/or flooding and cyclic reopening of airways (12). Pathological stretch is associated with cellular injury and activation of proinflammatory signaling cascades $(8,13,14)$. Attention has focused on stretch-activated mitogen-activated protein kinases and phosphatidylinositol 3-kinase signaling pathways in lung injury/inflammation caused by high-Vt ventilation (15-21). New data here demonstrate that lung stretch associated with MV also evokes an endogenous adaptive program distinct from these injury-associated pathways, limiting stretch-induced lung injury. Given the necessity of stretch for lung function, it is not surprising that the lung protects itself from stretch, although this concept has received relatively little attention.

The newly identified adaptive stretch response herein involves intracellular zinc and metallothionein (MT), both of which have broad cellular protective roles (22-37). MT is important for cellular 
Table 1. Top 10 rank-ordered stretch responsive genes in each cell type (metallothioneins [MTs] are highlighted)

\begin{tabular}{c|c|c|c}
\hline CCL-151 & CCL-153 & A549 & 16HBE \\
\hline MT1M & MT1M & MT1X & MT1M \\
\hline SNORA73A & MT1X & MT1F & HSPA6 \\
FBX025 & DNAJA4 & MT1G & SLCO1B3 \\
HM0X1 & HMOX1 & MT1E & HSPA6 \\
SNORD28 & MT1G & MT2A & PLA2G4A \\
SNORD116-21 & MT1F & BIRC3 & HAVCR1 \\
SCARNA9 & ANKRD1 & MT1L & MT1X \\
IMPAD1 & SERPINB2 & MT2A & HCD \\
SNORD27 & IL1A & MT1M & ACR2 \\
HSPH1 & HSPA6 & ANKRD1 & PPYR1 \\
\hline
\end{tabular}

zinc homeostasis through 7 zinc-binding sites (38), while MT expression is highly responsive to changes in zinc levels (39); this system normally tightly regulates cytoplasmic zinc levels. Zinc is an essential micronutrient (34, 40-42), and its tissue and plasma levels are influenced by dietary intake (38, 42). While severe zinc deficiency is rare in the developed world, moderate zinc deficiency is widespread, concentrated in elderly populations (42-45), and can be exacerbated in critically ill patients $(33,46-49)$. We demonstrate that both genetic MT deficiency and dietary zinc deficiency potentiate lung injury in mechanically ventilated mice, consistent with an essential role for the zinc/MT system in protecting the lung from injurious stretch. To demonstrate clinical relevance of our findings, we show that humans who go on to develop ARDS exhibit lower plasma zinc levels. Taken together, our results suggest that failure of essential stretch-adaptive responses, in this case associated with a remediable dietary deficiency among hospitalized patients, may play an important role in injury responses propagated by MV.

\section{Results}

Cell stretch promotes MT expression. We applied biaxial stretch (50) to fibroblast (CCL-151, 153) and epithelial (A549, 16HB14o-) cell lines, and performed microarray analysis. To minimize apoptosis/necrosis responses observed with cyclic stretch, we applied a single static stretch (18, 51, $52)$. With single, tonic stretch of large but physiological magnitude $(30 \%)(53,54)$, at 4 hours, MT family members (MT) were among the strongest stretch-responsive genes (Tables 1 and 2). Overabundance of $M T$ genes was confirmed by gene ontology, indicating 700- to 1,200-fold enrichment in $M T$ genes above what would be expected randomly (Table 3). In humans, $11 M T$-encoding genes have been identified: MT1 (8 subtypes: $M T 1 A, B, E, F, G, H, M$, and $X)$ and $M T 2 A$ are the most widely expressed isoforms. The striking commonality in expression of genes of this family across diverse cell types suggested a highly conserved mechanism of induction in response to stretch and hinted at broad influence.

Replicate cell culture experiments confirmed potent (3- to 100-fold) stretch induction of $M T 1 G, M$, and $X$ message by real-time quantitative PCR (qPCR) (Figure 1A) across 4 cell lines. Static stretch rapidly and transiently increased expression of these genes (Figure 1B). Expression of all 3 genes was highly responsive to the magnitude of stretch applied, exhibiting robust induction with as little as $10 \%$ stretch (Figure 1C), clearly within the physiological range of stretch relevant to intact lung alveoli (54). We also examined $M T 1 G, M$, and $X$ expression in primary human lung microvascular endothelial cells and CCL-151 fibroblasts subjected to $20 \%$ cyclic stretch for 4 hours (sinusoidal waveform, frequency $0.33 \mathrm{~Hz}$ ). We observed a slightly different pattern of $M T$ gene expression, but confirmed significant induction of $M T 1 X$ expression after cyclic stretch in endothelial cells (Figure 1D) and of MT1G expression after cyclic stretch in fibroblasts (Figure 1E). MT induction was also confirmed at the protein level after cyclic stretch in fibroblasts (Figure 1F).

MT expression is an adaptive response that protects the lung from injurious stretch. Analysis of publicly deposited microarrays demonstrated that the murine homologs $M t 1$ and $M t 2$ are strongly upregulated in animals by high-Vt ventilation $(21,55-58)$ (Table 4), though none of these studies focused on MT in ventilator-induced lung injury (VILI). We confirmed potent induction of $M t$ expression by mechanically ventilating $129 / \mathrm{Sv}$ male mice for 4 to 8 hours with a Vt of $24 \mathrm{ml} / \mathrm{kg}$, and measuring Mt1 and Mt2 mRNA levels in whole-lung homogenates ( $n=5$ mice/time point). Mt1 expression peaked at 6 hours ( $\sim 5$-fold increase), while $M t 2$ peaked at 6 hours ( 6-fold increase) (Figure 2A). Western blotting confirmed MT induction in the lung at the protein level over a similar time course (Figure $2 \mathrm{~B}$ ). To test the role $M t$ expression plays in VILI, we used mice deficient in $M t 1$ and Mt2 expression (Mt1/2 $2^{(-/)} ; 129 \mathrm{~S} 7 / \mathrm{SvEvBrd}-\mathrm{Mt}^{\mathrm{tm} I \mathrm{Bri}}$ $\left.M t 2^{t m l B r}\right)$ (59). The mice develop normally and exhibit no baseline respiratory phenotype. $\mathrm{Mt} 1 / 2^{(--)}$mice exhibited significantly larger increases in lung elastance versus strainmatched (129S1/SvImJ) controls $\left(\mathrm{Mt1} / 2^{(+/+)}\right)$after 6 and 8 hours of MV (Figure 2C). Interestingly, divergence in elastance changes between the 2 groups (Figure 2C) was

Table 2. Rank order among stretchresponsive genes for metallothioneins (MTs)

\begin{tabular}{ccccc}
\hline & CCL-151 & CCL-153 & A549 & 16HBE \\
MT1X & 90 & 2 & 1 & 7 \\
MT1G & 107 & 5 & 3 & 95 \\
MT1M & 1 & 1 & 9 & 1 \\
\hline
\end{tabular}


Table 3. Computational enrichment analysis of stretch-responsive genes common to all 4 cell types (top 7)

\begin{tabular}{lccc}
\hline Term & $\boldsymbol{P}$ value & Fold Enrichment & Genes \\
cadmium & $1.55 \times 10^{-12}$ & 1202 & MT1A, MT1E, MT1G, MT1L, MT1M, MT1X \\
region of interest:Alpha & $4.75 \times 10^{-12}$ & 956 & MT1A, MT1E, MT1G, MT1L, MT1M, MT1X \\
region of interest:Beta & $4.75 \times 10^{-12}$ & 956 & MT1A, MT1E, MT1G, MT1L, MT1M, MT1X \\
metal ion-binding site:Divalent metal cation; cluster A & $7.47 \times 10^{-12}$ & 869 & MT1A, MT1E, MT1G, MT1L, MT1M, MT1X \\
metal ion-binding site:Divalent metal cation; cluster B & $7.47 \times 10^{-12}$ & 869 & MT1A, MT1E, MT1G, MT1L, MT1M, MT1X \\
metal-thiolate cluster & $1.09 \times 10^{-11}$ & 801 & MT1A, MT1E, MT1G, MT1L, MT1M, MT1X \\
IPR018064:Metallothionein, vertebrate, metal binding site & $1.29 \times 10^{-11}$ & 757 & MT1A, MT1E, MT1G, MT1L, MT1M, MT1X
\end{tabular}

greatest after the time point when MT expression peaks (Figure 2, A and B), consistent with an adaptive role for stretch-induced $M t$ expression that protects the lung from high stretch.

Additionally, Mt1/2 $2^{(-)}$mice exhibited a more pronounced proinflammatory response, with significant increases in bronchoalveolar lavage (BAL) total cells, neutrophils, and IL-6 levels (Figure 2, D and E). In addition, a significant increase in BAL protein in $\mathrm{Mt} 1 / 2^{(-/)}$mice after 8 hours of MV compared with $\mathrm{Mt} 1 / 2^{(+/+)}$ mice was consistent with enhanced disruption of barrier function in the absence of $M t$ expression (Figure $2 \mathrm{~F})$. Lung histology confirmed early lung damage, with patchy congestion in $\mathrm{Mt} 1 / 2^{(--)}$, but not mechanically ventilated $\mathrm{Mt} 1 / 2^{(+/+)}$mice, and increased Gr-1 staining (neutrophils) in lung tissue (Figure 2, G and $\mathrm{H}$ ). Blinded analysis by a lung pathologist confirmed an increased lung injury score (60) and increase in the number of neutrophils per high-power field in the $\mathrm{Mt} 1 / 2^{(-/)}$mechanically ventilated mice versus the mechanically ventilated $\mathrm{Mt1} / 2^{(+/+)}$mice (Figure 2, I and $\mathrm{J}$ ). Before MV, there were no significant differences in BAL cell counts, IL-6 levels, total protein (Figure 2, D and F), or gross histological differences between $\mathrm{Mt} 1 / 2^{(-/-)}$and $\mathrm{Mt} 1 / 2^{(+/)}$mice (data not shown). While extravascular lung water or wet-to-dry ratios were not specifically measured in these studies, the presence of increased BAL protein along with the other indices of increased lung injury in $\mathrm{Mt1} / 2^{(--)}$mice supports increased lung injury in these animals. Taken together, these results support a pivotal role for MV-induced $M t$ expression in limiting lung injury, neutrophil accumulation, and vascular leak in mice ventilated with high Vt's and exposed to accompanying high levels of cellular stretch.

Stretch induction of MT expression is zinc and MTF1 dependent. While the mechanism underlying stretch induction of $M T$ gene expression has not been described, MT genes are potently induced by exposure to zinc and xenobiotic metals $(39,61,62)$. In CCL-151 human lung fibroblasts, increasing exogenous zinc in the media above standard levels resulted in rapid and dose-dependent induction of $M T$ gene expression (Figure 3, A and B). Next we tested whether enhanced $M T$ expression in response to cell stretch requires endogenous zinc. Zinc chelation resulted in $\sim 70 \%-80 \%$ attenuation of the stretch response in $M T 1 G$ and $M T 1 M$ transcripts (Figure 3C).

Enhancement of $M T$ expression in response to zinc and other metals requires metal regulatory transcription factor 1 (MTF1), which translocates from the cytoplasm to the nucleus upon zinc binding, and interacts with a metal response element (MRE) in promoter sequences of metal-responsive genes (63-65). Using A549 epithelial cells (Figure 3D), we observed that stretch induces MTF1 transcriptional activity, as measured by an MRE-driven promoter-reporter assay. When we knocked down MTF1 expression with RNAi (Figure 3E), we observed complete attenuation of stretch-induced MT1G and MT1X expression in

Table 4. Published microarray datasets from mice ventilated with high tidal volumes

\begin{tabular}{lcccc}
\hline GEO DATASET & GSE11434 (58) & GSE9208 (57) & GSE11662 (21) & GSE2368 (55) \\
Tidal Volume, duration & $20 \mathrm{ml} / \mathrm{kg}, 3 \mathrm{~h}$ & $30 \mathrm{ml} / \mathrm{kg}, 2 \mathrm{~h}$ & $30 \mathrm{ml} / \mathrm{kg}, 4 \mathrm{~h}$ & $17 \mathrm{ml} / \mathrm{kg}, 6 \mathrm{~h}$ \\
Mt1 & $3.58[50]$ & $3.78[17]$ & $2.83[31]$ & $7.67[4]$ \\
Mt2 & $3.72[48]$ & $4.99[9]$ & $3.68[16]$ & $11.16[1]$
\end{tabular}

Data are fold change in transcript levels in mechanically ventilated mice relative to spontaneously breathing controls. Reference numbers are in parentheses, and gene rank within each study is included in square brackets. 
A

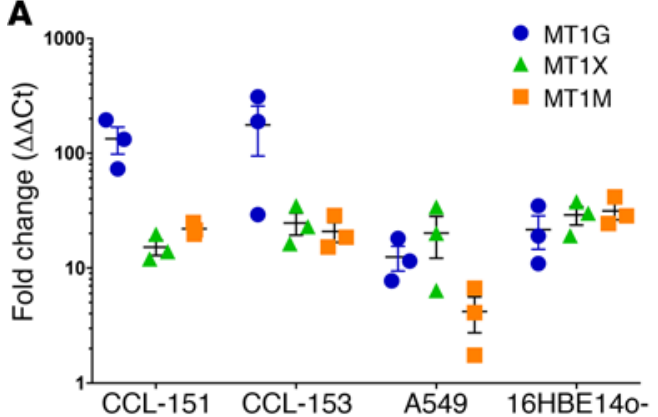

B

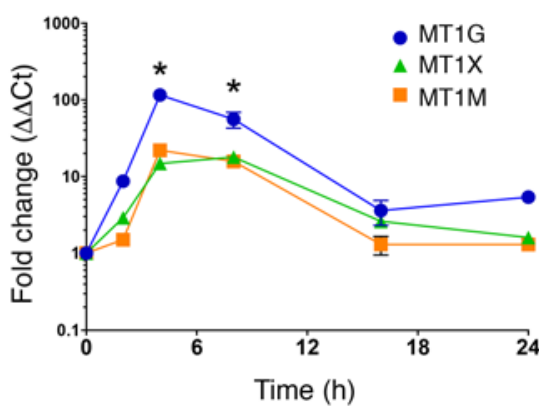

C

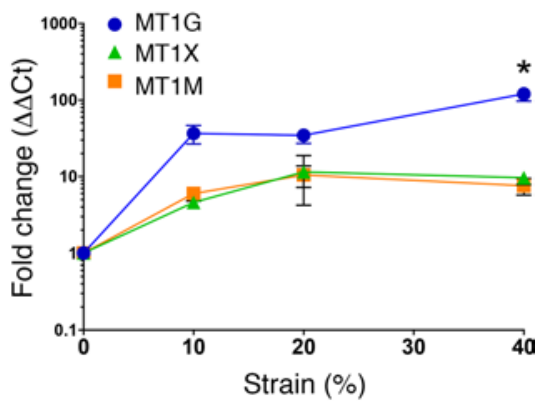

D

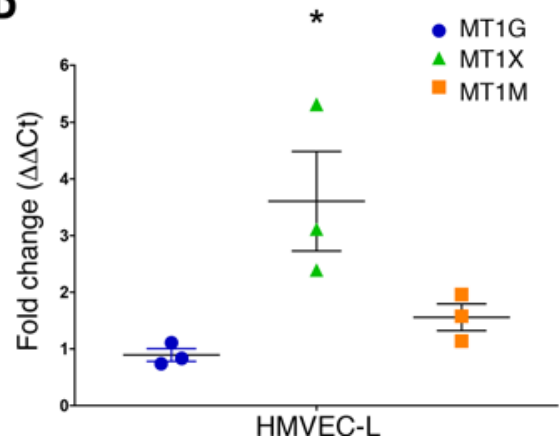

E

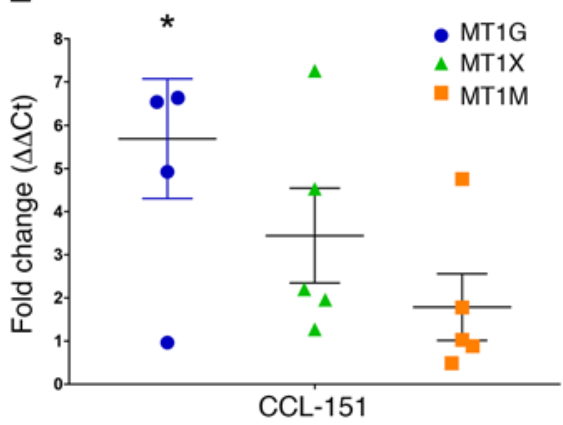

F

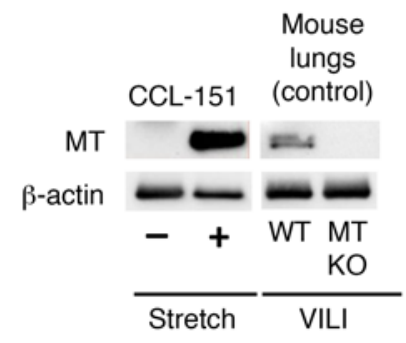

Figure 1. Metallothionein (MT) genes are highly responsive to stretch. (A) CCL-151, CCL-153, A549, and 16HBE140- cells were exposed to tonic stretch (30\% strain) for 4 hours, and then replicate analysis (validating the microarray analysis in Tables 1 and 2 ) of stretch-induced expression by real-time quantitative PCR (qPCR) for MT1G, MT1M, and MT1X transcript levels $(n=3)$ expressed relative to time-matched controls $(n=3)$ was performed. (B) CCL-151 cells were tonically stretched ( $30 \%$ strain) for the indicated periods of time before RNA harvest and gene expression analysis by qPCR. An independent 6-well BioFlex plate was used for each time point ( $n=3$ stretched and 3 control wells per time point). ${ }^{*} P<0.05$ versus unstretched control for all 3 genes by Kruskal-Wallis test with Dunn's multiple comparison's test. (C) CCL-151 cells were exposed to tonic stretch with amplitudes of $10 \%$, $20 \%$, and $40 \%$ strain and assessed for transcript level changes after 4 hours. Each strain increment was measured from an independent 6-well BioFlex plate ( $n=3$ stretched and 3 control wells per increment of strain). ${ }^{*} P<0.05$ versus unstretched control for MT1G by Kruskal-Wallis test with Dunn's multiple comparisons test. (D) HMVEC-L cells and (E) CCL-151 fibroblasts were cyclically stretched 20\% (sinusoidal waveform) at $0.33 \mathrm{~Hz}$ for 4 hours and probed for MT transcript levels by qPCR ( $n=3$ stretched and 3 time-matched controls for endothelial cells and $n=5$ stretched and 5 time-matched controls for fibroblasts). ${ }^{*} P<0.05$ versus control, Student's 2-tailed $t$ test. (F) CCL-151 cells subjected to cyclical stretch as in panel $\mathbf{E}$ or unstretched control cells (pooled from 3 separate wells) were harvested for protein and analyzed by Western blotting using MT and $\beta$-actin (loading control) antibodies. As a control to confirm specificity of the MT antibody, lungs harvested from WT and MT knockout (KO) mice subjected to ventilator-induced lung injury (VILI) for 4 hours with $24 \mathrm{ml} / \mathrm{kg}$ tidal volume, as described in more detail in Figure 2, were analyzed by Western blotting using the same antibodies.

A549 cells and lung fibroblasts (Figure 3F). These results reveal to the best of our knowledge a previously unknown effector pathway linking cell stretch to $M T$ expression, through either activation or mimicry, of an intracellular zinc signaling response.

Experimental zinc deficiency primes the lung for VILI. Based on the in vitro role for zinc in stretch-induced MT expression, and the widespread occurrence of zinc deficiency in humans $(42,66)$, we investigated whether dietary zinc deficiency may prime the lung for injury when exposed to MV. We generated zincdeficient animals by feeding mice a zinc-deficient diet for 3 weeks and observed a similar decline in plasma zinc levels as did Knoell et al. (67), mirroring clinically relevant mild to moderate human zinc deficiency (Figure 4A). At baseline, the zinc-deficient diet did not result in significant lung injury or inflammation, nor changes to baseline respiratory mechanics nor body weights (Figure 4, B-E).

To establish the relevance of zinc deficiency in response to MV, we evaluated lung injury in control and zincdeficient mice ventilated for up to 8 hours with a modest Vt of $15 \mathrm{ml} / \mathrm{kg}$ to more closely model the lower Vt's used in patients with lung injury, as well as a higher Vt of $24 \mathrm{ml} / \mathrm{kg}$ to induce a sufficiently intervenable injury. We observed that MV was well tolerated in control mice, but zinc-deficient mice exhibited increased lung injury and inflammation, with increases in lung elastance, and increased BAL total cells, protein, and IL-6 (Figure $5, \mathrm{~A}, \mathrm{~B}$, and D-F). The increased injury after VILI observed in zinc-deficient mice correlated with decreased lung MT protein expression compared with WT mice subjected to VILI (Figure 5C). In examining lung tissue 
A

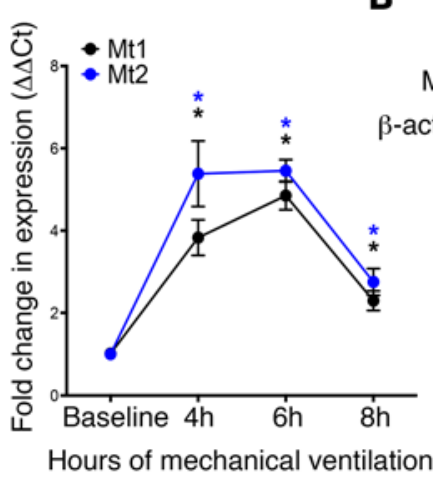

C

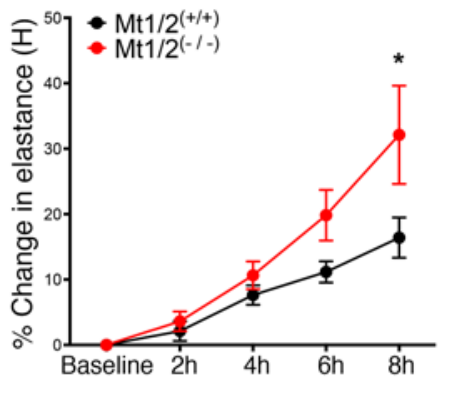

Hours of mechanical ventilation
D

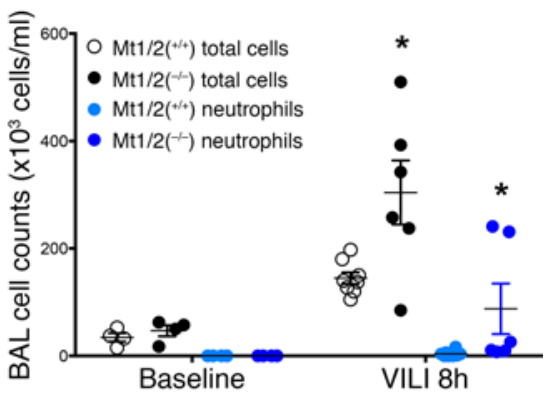

E

है

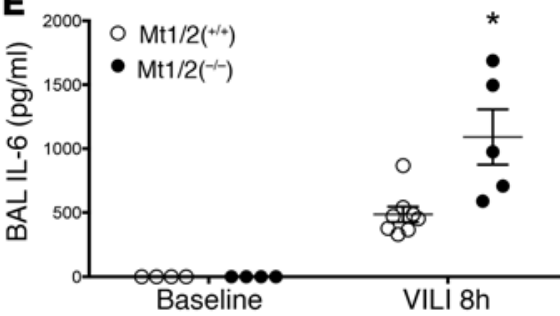

$F$

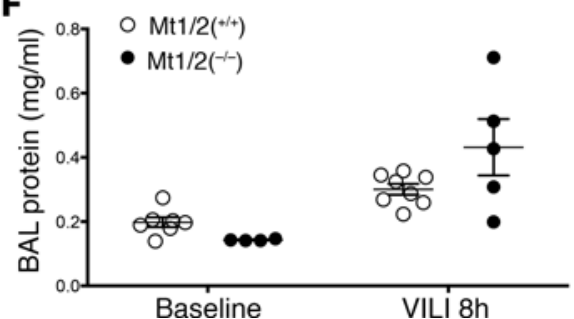

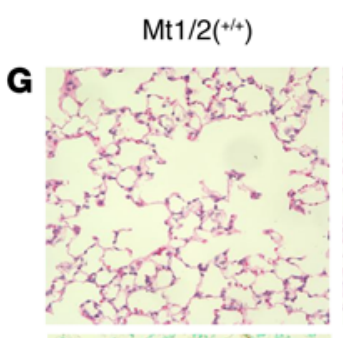

H

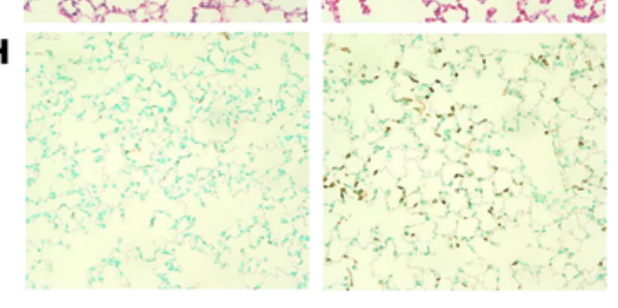

$\mathrm{Mt} 1 / 2\left({ }^{(-)}\right)$

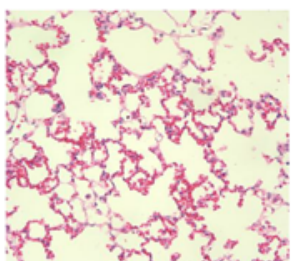

I

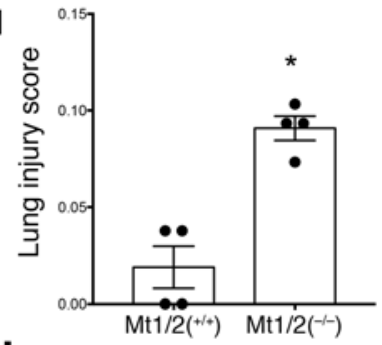

J

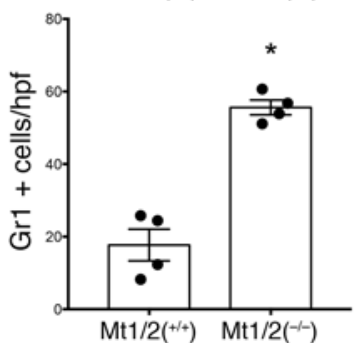

Figure 2. Mt1/2-deficient mice exhibit enhanced lung injury in response to ventilator-induced lung injury. (A) WT mice were subjected to mechanical ventilation using a Flexivent ventilator with a tidal volume of $24 \mathrm{ml} / \mathrm{kg}$, followed by lung harvest and assessment of Mt1 (black circles) and Mt2 levels (blue squares) using real-time quantitative PCR (qPCR) ( $n=3-5$ mice per time point). ${ }^{*} P<0.001$ versus baseline by 1-way ANOVA with Newman-Keuls post-hoc test. (B) WT mice subjected to mechanical ventilation as in panel A were assessed for metallothionein (MT) lung protein levels, with $\beta$-actin as a loading control (pooled from 4 mice/time point). (C) $\mathrm{Mt} 1 / 2^{(--)}$(red squares) and $\mathrm{Mt} 1 / 2^{(+/)}$control mice (black circles) were subjected to mechanical ventilation and lung stiffness (elastance, $\mathrm{H}$ ) was measured hourly. The percentage change in elastance was determined over the time course of mechanical ventilation ( $n=$ $19-25$ at $0-6$ hours, $n=8-12$ at 8 hours for each genotype). ${ }^{*} P<0.05$ versus Mt1/2(+/) by 2 -way ANOVA with Bonferroni's post-hoc test. (D-F) After 8 hours of mechanical ventilation ( $n=4-8 /$ group, denoted MV $24 \mathrm{ml} / \mathrm{kg}$ ), bronchoalveolar lavage (BAL) fluid was collected and analyzed for total and differential cell counts (D), IL-6 levels by ELISA (E), and BAL total protein levels $(\mathbf{F}) .{ }^{*} P<0.05$ versus Mt1/2(+/+) ventilation-induced lung injury (VILI) at 8 hours by 2 -way ANOVA, with Bonferroni post-hoc test. No difference in baseline levels for any of these outcomes was observed between the 2 groups prior to mechanical ventilation. ( $\mathbf{G}$ and $\mathbf{H}$ ) After 8 hours of mechanical ventilation lungs were harvested and fixed at $30 \mathrm{cmH}_{2} \mathrm{O}$, paraffin embedded, and then stained with $\mathrm{H} \& \mathrm{E}$ (C), or with antibody against $\mathrm{Gr} 1$ to visualize neutrophils $\mathbf{( H )}$. Original magnification $\times 200$. Histologic lung injury was quantified using a lung injury score as referenced in the text (I), and neutrophil infiltration was quantified by counting the Gr1-positive neutrophils per high-power field (hpf) (J). (I and J) $n=4 /$ group, with each data point representing 1 mouse and the average of 9 hpfs expressed as mean $\pm S E M .{ }^{*} P<0.05$ versus Mt $1 / 2^{(++)}$by Mann-Whitney $U$ test.

homogenates for changes in a panel of proinflammatory markers, we were unable to detect significant differences between zinc-deficient and control mice exposed to MV (Supplemental Table 1; supplemental material available online with this article; https://doi.org/10.1172/jci.insight.86507DS1), although there were trends toward increased IL-12p40, MCP1, and IL-33 in zinc-deficient mice.

Because MV is often required in preexisting lung injury, we characterized the relevance of zinc deficiency by using a 2-hit model by administering LPS (Pseudomonas; see ref. 68) 24 hours before MV (Vt 15 $\mathrm{ml} / \mathrm{kg}$ ). As with MV alone, dietary zinc deficiency significantly exacerbated lung injury, with a significant increase in lung elastance, BAL protein, and BAL IL-6 in zinc-deficient LPS+MV mice (Figure 6, A-C). We observed a nonsignificant increase in BAL total cells and neutrophils in the zinc-deficient group (Figure 6D), although there was a robust, primarily neutrophilic inflammation in both groups relative to MV alone (vs. Figure 5D) as expected with LPS exposure. We observed increased IL-6 levels in lung tissue homogenates (Supplemental Table 1), and identified significant increases in proinflammatory mediators 
A

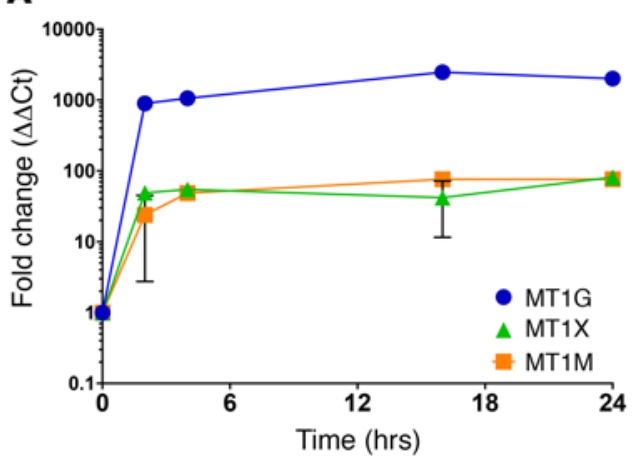

D

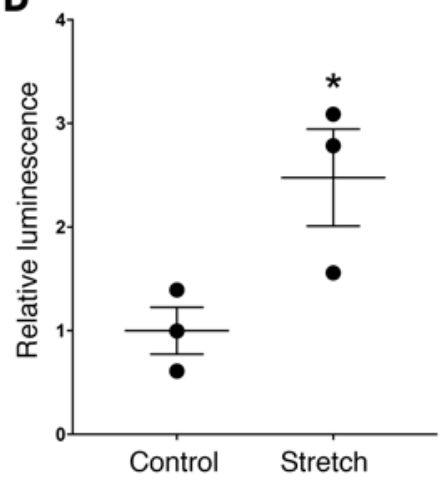

B

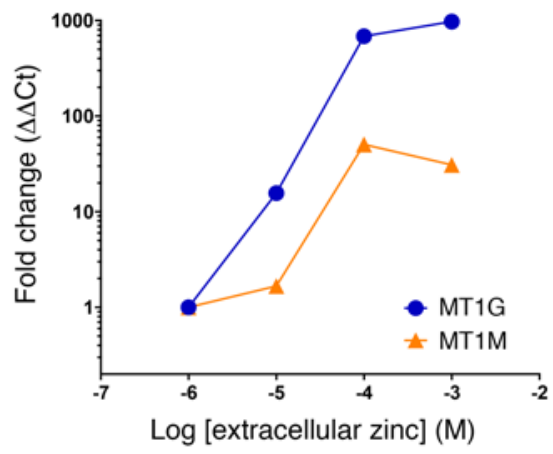

E

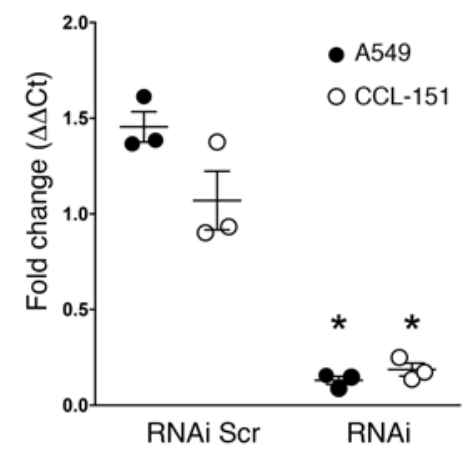

C

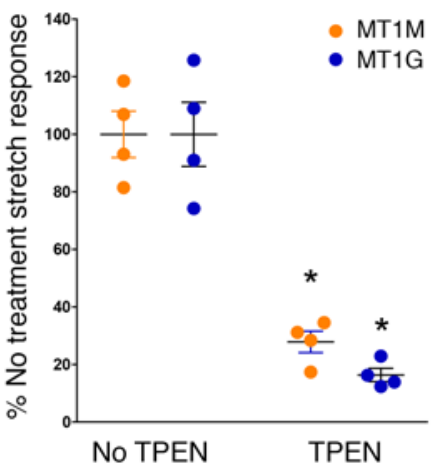

$\mathbf{F}$

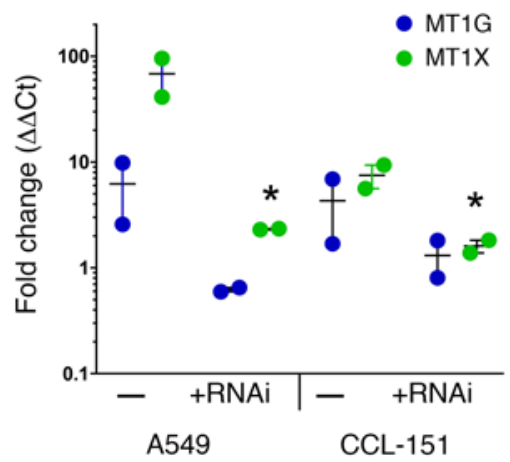

Figure 3. Stretch-induced metallothionein (MT) expression is zinc and MTF1 dependent. (A) CCL-151 cells were treated with $100 \mu \mathrm{M}$ extracellular zinc (basal extracellular free $\mathrm{Zn}^{2+}$ level in media is $\sim \mu \mathrm{M}$ ) for $2,4,16$, and 24 hours and probed for MT transcript levels by real-time quantitative PCR ( $q P C R$ ) ( $n$ = 2 per time point). (B) CCL-151 cells were treated with extracellular zinc for 4 hours and probed for MT1M and MT1C transcript levels by qPCR. Responses were normalized to basal extracellular free $\mathrm{Zn}^{2+}$ level $\sim 1 \mu \mathrm{M}(n=1$ per dose). (C) Intracellular and extracellular zinc were chelated with membrane-permeant TPEN $(10 \mu \mathrm{M})$ to an estimated level below $1 \mathrm{pM}$ intra- and extracellularly, 15 minutes prior to stretching CCL-151 cells for 4 hours. Stretched and timematched control cells were then probed for MT transcript levels and responses normalized to TPEN-free stretch induction ( $n=4$ samples per measurement). ${ }^{*} P<0.05$, Student's 2-tailed $t$ test. (D) A549 cells transfected with MTF1-responsive luciferase reporter were exposed to tonic stretch (30\% strain) for 4 hours prior to measuring luminescence $(n=3)$. ${ }^{*} P<0.05$, Student's 2 -tailed $t$ test. (E) Treatment with siRNA (50 nM) targeting MTF1 (+RNAi) for 72 hours decreased transcript levels in CCL-151 and A549 cells relative to control (fold change 1.0) $(n=3)$, while scrambled siRNA (+RNAi scr) did not affect MTF1 transcript levels $(n=3) .{ }^{*} P<0.05$ versus both control and scrambled siRNA, Student's 2-tailed $t$ test. (F) Knockdown of MTF1 with siRNA (+RNAi) prevented stretch-induced expression of MT1X in A549 and CCL-151 cells, with similar trends observed for MT1G $(n=2)$. ${ }^{*} P<0.05$, Student's 2-tailed $t$ test.

IL-1A and IL-12p40 in zinc-deficient mechanically ventilated mice (Figure 6, E and F). These results contrast with the indistinguishable tissue cytokine levels found at baseline in zinc-deficient and control mice (Figure 4C), emphasizing that effects of this dietary deficiency on lung function and inflammation are amplified when mechanical stretch occurs in the setting of preexisting lung injury, as is often the case in patients requiring MV.

VILI in mice leads to plasma zinc deficiency, and plasma zinc levels correlate with development of ARDS in critically ill humans. Our data demonstrate the importance of preexisting zinc deficiency in priming the lung for injury from MV. A related clinically relevant question is whether individuals with normal zinc levels are predisposed to develop zinc deficiency during critical illness and MV. To evaluate this, WT mice (C57BL/6 mice, 6 weeks old) on standard chow with preexisting normal zinc levels were subjected to 8 hours of MV $(15 \mathrm{ml} / \mathrm{kg}$ ). Interestingly, we observed a significant reduction in plasma zinc after 8 hours of VILI (Figure $7 \mathrm{~A}$ ); this reduction was evident as early as 4 hours after initiation of VILI (data not shown). Even preexisting normal zinc levels may not preclude development of enhanced susceptibility to VILI.

Because our findings in mice demonstrated that dietary zinc deficiency alone enhances injury associated with MV in the presence of lung inflammation, we sought to determine plasma zinc levels in critically ill patients with ARDS compared with control subjects, as well as intensive care unit (ICU) subjects with the systemic inflammatory response syndrome (SIRS) and sepsis. We examined plasma 
A

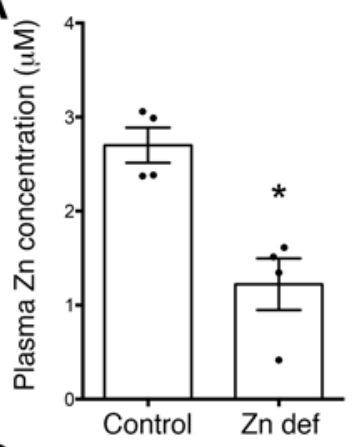

C

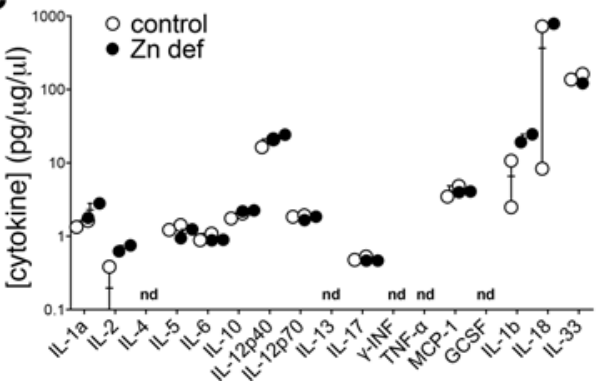

B

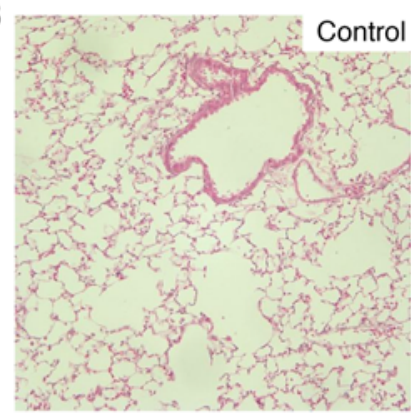

D

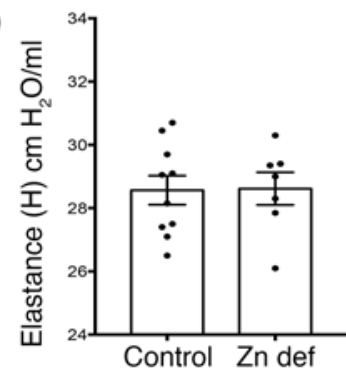

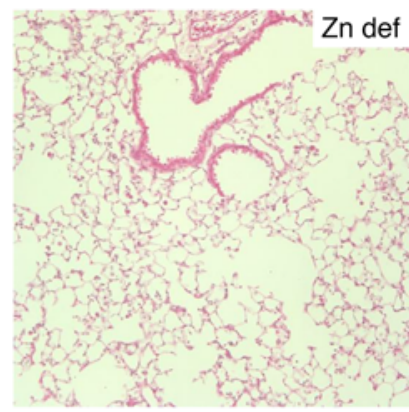

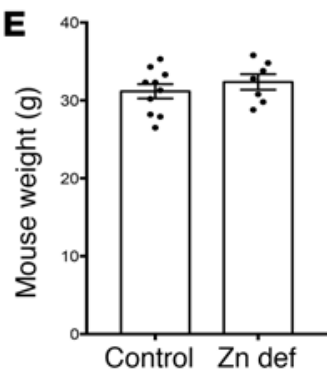

Figure 4. Zinc-deficient mice have lower zinc plasma concentration with no significant baseline differences in injury, inflammation, respiratory mechanics, or body weight. (A) C57BL/6 mice were fed a standard diet (control, Picolab, 5058, 120 ppm Zn) or a zinc-deficient diet (Zn def, Harlan Teklad, TD85419; 1 ppm Zn) for 3 weeks. Plasma was collected and assessed for zinc levels. Plasma zinc levels in the zinc-deficient mice were significantly reduced in comparison with control mice, $n=4$ /group, data presented as mean \pm SEM. ${ }^{*} P<0.05$ by Mann-Whitney $t$ test (nonparametric 2-tailed $t$ test). (B) Control and zinc-deficient mouse lungs were fixed at $30 \mathrm{cmH}_{2} \mathrm{O}$, paraffin embedded, and then stained with $\mathrm{H} \& \mathrm{E}$. Original magnification, $\times 200$. Lungs from both groups were normal in appearance. (C) Control and zinc-deficient lung tissue homogenates ( $n=3$ /group) were assayed for a panel of inflammatory cytokines by multiplex ELISA (nd denotes levels of cytokine were not detectable in sample). No significant differences were found between the groups. (D) Respiratory mechanics were assessed at baseline using the Flexivent mouse ventilator in zinc-deficient and control mice. No difference was found in tissue elastance between the groups; $n=9$ in control and 7 in zinc-deficient group, data presented as mean \pm SEM. (E) Body weights were measured in zinc-deficient and control mice after 3 weeks on a zinc-deficient or control diet before performing mechanical ventilation or LPS exposure experiments. No significant differences were found between the groups; $n=10$ in control and 7 in zinc-deficient group, data presented as mean \pm SEM.

collected from patients upon ICU admission $(69,70)$ (Supplemental Tables 2 and 3 ) and who went on to require MV and develop ARDS ( $n=21)$, compared with ICU control subjects without sepsis or ARDS $(n=3)$ as well as non-ICU healthy control subjects $(n=4)$, and subjects with sepsis $(n=62)$ and SIRS $(n=26)$. There was no difference in plasma zinc between ICU controls and healthy controls, so we combined these groups for comparison with subjects who went on to develop ARDS, sepsis, or SIRS. We observed a significant reduction in plasma zinc in subjects who developed ARDS compared with controls (Figure 7B) that was even beyond that of other critically ill subjects with sepsis or SIRS, supporting a possible link between plasma zinc and enhanced injury in the setting of lung injury and MV.

To further characterize the association between ARDS and reduction in plasma zinc levels, we measured plasma IL-18 and IL-6 levels (given prior studies demonstrating the potential of these cytokines to serve as biomarkers in critical illness; see refs. 3,69 ) and found that lower zinc levels were associated with a higher plasma IL-6 levels ( $r=0.21, P=0.03$, Supplemental Table 3). However, zinc levels were not associated with IL-18 levels $(r=0.06, P=0.50)$. This is interesting and supportive of the relevance of the murine model to the human data, given that zinc deficiency was associated with elevated BAL IL-6 levels in lung injury (Figure 6). Furthermore, associations between zinc levels and 23 variables (including age, APACHE II score, Glasgow Coma Scale, lactate, race, transfusions, ventilated status, heart disease, heart failure, coronary artery disease, acute kidney injury, diabetes mellitus, liver disease, obesity, use of total parenteral nutrition, chronic obstructive pulmonary disease, chronic kidney disease, chronic renal insufficiency, in-hospital mortality, use of pressors, and malignancy) were examined (Supplemental Table 3), and no significant bivariate associations were found. We next investigated whether there was 
A

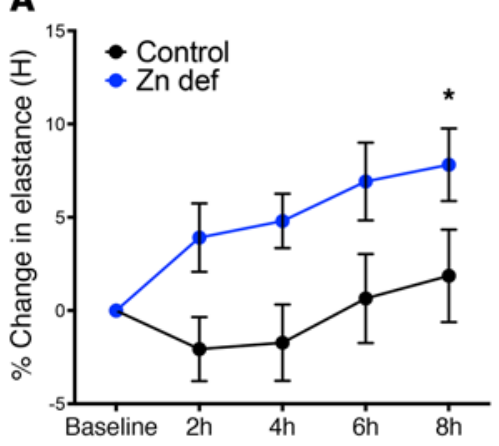

Hours of mechanical ventilation
B

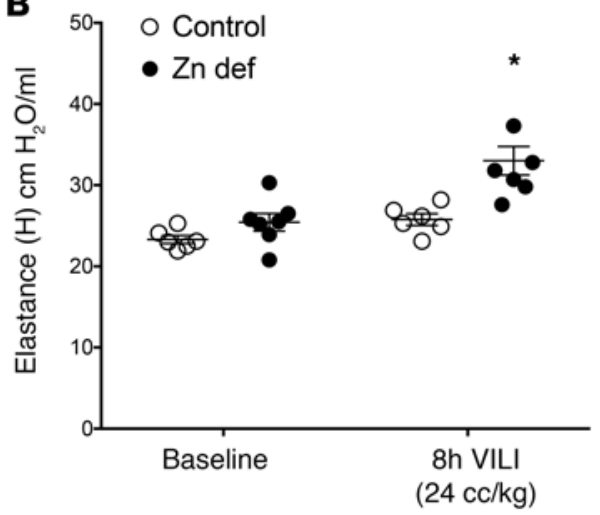

C

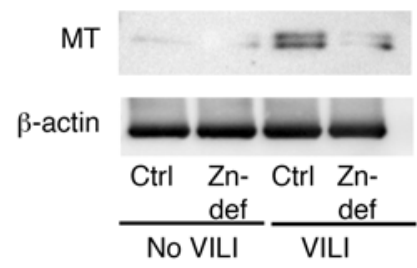

D

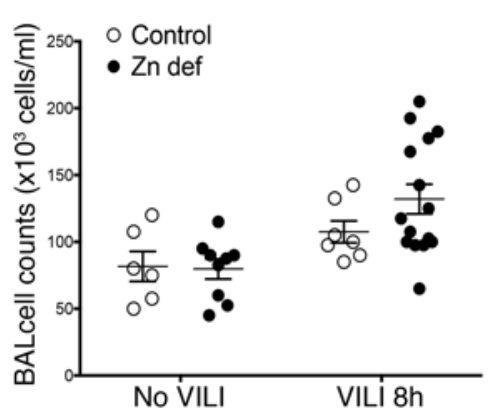

$\mathbf{E}$

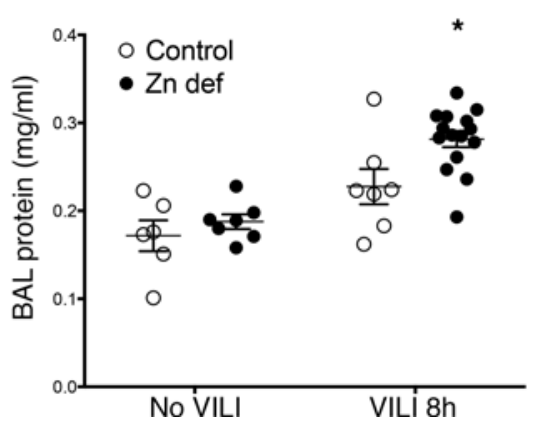

$\mathbf{F}$

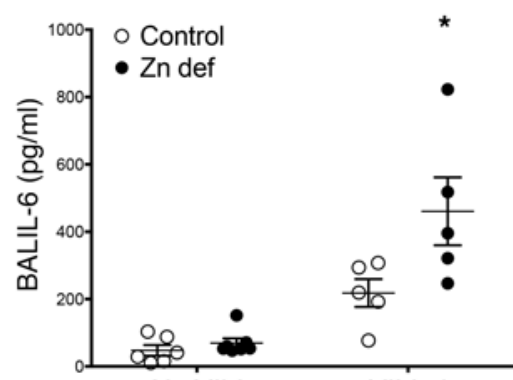

No VILI VILI 8h

Figure 5. Zinc deficiency promotes VILI and correlates with lower metallothionein (MT) lung protein levels. (A) Zinc-deficient mice $(n=15)$ exhibited significantly increased physiologic dysfunction (increased elastance) compared with control mice $(n=7) .{ }^{*} P<0.05$ versus control by 2 -way repeated measures ANOVA after mechanical ventilation with modest tidal volumes $(15 \mathrm{ml} / \mathrm{kg}$ tidal volume for 8 hours, percentage change from baseline) as well as with injurious tidal volumes ( $24 \mathrm{ml} / \mathrm{kg}$ for 8 hours) with a significant increase in elastance (B). ${ }^{*} P<0.05$ by 2 -way ANOVA with Bonferroni post-hoc test, $n=6$ mice/ control and 7 mice/zinc-deficient group; data presented as mean \pm SEM. (C) Lungs were harvested from mice subjected to ventilator-induced lung injury (VILI) as in panel B ( $n=3-4 /$ group) and pooled, and then harvested for protein and analyzed by Western blotting for MT or loading control ( $\beta$-actin). (D-F) After 8 hours of mechanical ventilation with modest tidal volumes (mechanical ventilation $15 \mathrm{ml} / \mathrm{kg}$ ), bronchoalveolar lavage (BAL) fluid was collected and analyzed for (D) total cell counts (baseline $n=6-9$ / group, VILI $n=7-15$ per group for both diets); (E) BAL total protein levels (baseline $n=6-7 /$ group, VILI $n$ $=7-15 /$ group, for both diets), ${ }^{*} P<0.05$ by 2-way ANOVA versus control diet 8-hour VILI, with Bonferroni post-hoc test; and (F) BAL IL-6 levels (baseline $n=$ 6 -7/group, VILI $n=5$ /group for both diets), ${ }^{*} P<0.05$ by 2-way ANOVA, with Bonferroni post-hoc test versus control. All data are presented as mean \pm SEM. No difference in baseline levels for any of these outcomes was observed between to the 2 groups prior to mechanical ventilation.

a decreasing trend across the diagnosis groups according to severity. We tested multiple variable models that potentially included APACHE II score, malignancy, IL-6 plasma levels, diabetes mellitus, and liver disease as covariates. Only APACHE II and IL-6 contributed to the model significantly as covariates. In the multiple variable model, there was a significant decreasing linear trend across the ordered groups (Figure 7B and Supplemental Table 3) from control highest down to ARDS lowest $(P=0.02)$. The contrast between ARDS and all others combined was also significant $(P=0.004)$. Further, after an adjustment for multiple testing for ARDS versus each of the other 3 groups, the contrast between ARDS and control remained significant $(P<0.05)$.

\section{Discussion}

MV is essential in patients with respiratory failure, but also subjects lungs to high stretch, propagating lung injury (12). Protective ventilation minimizes mechanical stress by limiting Vt's and inspiratory pressures, and by keeping lungs open so that ventilation is distributed to the largest possible fraction of alveoli. It is not possible to completely shield the lung from stretch, particularly in heterogeneously injured lungs, and mortality even in the presence of protective strategies remains high (10). Our results demonstrate that the healthy lung has an endogenous stretch-activated response that is inherently adaptive/protective; inability to mount protective responses may promote lung injury by reducing tolerance for stretch. Specifically, we found that MT genes are prominently upregulated by stretch in human lung cells, and 
A

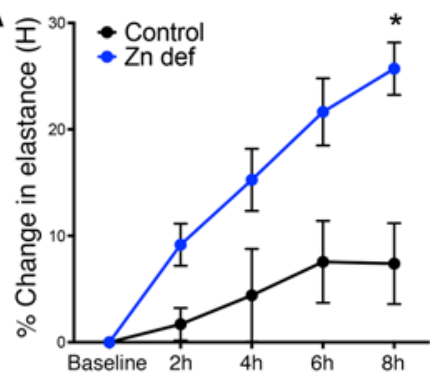

Hours of mechanical ventilation

D

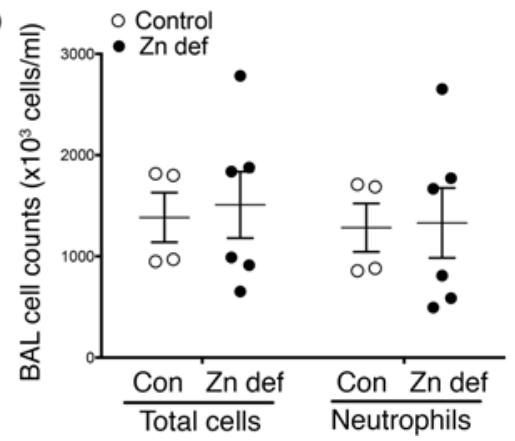

B

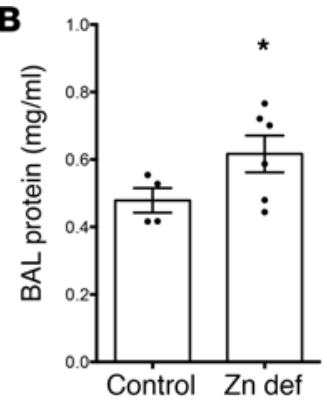

$\mathbf{E}$

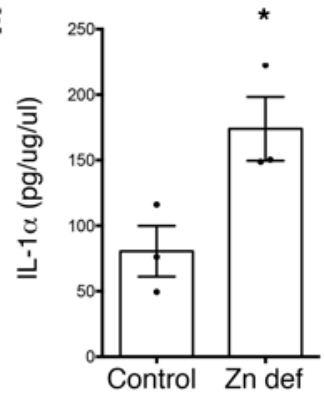

C
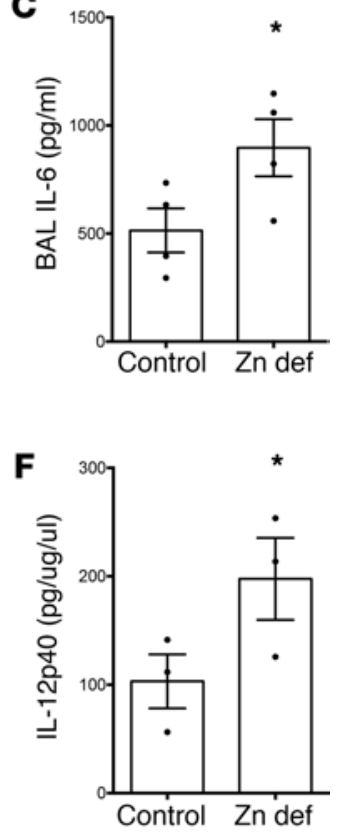

Figure 6. Zinc deficiency exacerbates injury from mechanical ventilation after endotoxin exposure. (A) Zincdeficient mice exhibit more pronounced physiologic dysfunction (increased elastance) compared with control mice when subjected to mechanical ventilation ( $15 \mathrm{ml} / \mathrm{kg}$ tidal volume for 8 hours) beginning 24 hours after nebulized endotoxin exposure. Elastance was measured hourly on the Flexivent ventilator, and the percentage change from baseline to 8 hours was calculated ( $n=4-6$ /group). ${ }^{*} P<0.05$ versus control diet by 2-way repeated measures ANOVA. (B-D) After 8 hours of LPS+ventilator-induced lung injury (VILI), bronchoalveolar lavage (BAL) fluid was collected and analyzed for (B) total protein levels (baseline $n=6 /$ group, VILI $n=4-6$ / group), ${ }^{*} P<0.05$ by 2 -way ANOVA, with Bonferonni post-hoc test including baseline data from Figure 5D; (C) IL-6 levels (baseline $n=6 /$ group, VILI $n=4$ /group), ${ }^{*} P<0.05$ by 2-way ANOVA, with Bonferroni post-hoc test using baseline data from Figure 5E; and (D) total and differential cell counts ( $n=4-6 / g r o u p)$. All data presented as mean \pm SEM. (E and $\mathbf{F}$ ) Lung tissue homogenate analysis from multiplexed assays revealed increased IL-1 $\alpha$ and IL-12p40 in zinc-deficient mice exposed to LPS plus mechanical ventilation. ${ }^{*} P<0.05$ by 2-way ANOVA, with Bonferroni post-hoc test, using control data included in Supplemental Table I; data presented as mean \pm SEM.

by high-Vt ventilation in animals. We demonstrated that deficiency of $M t 1$ and $M t 2$ expression does not alter baseline lung function, but significantly compromises the lung's ability to cope with high-Vt ventilation. Based on the necessity for zinc and the zinc-dependent transcription factor MTF1 in mounting stretch-induced expression of human MT genes, we examined the role of dietary zinc deficiency in potentiating lung injury in response to MV alone, and MV of lungs exposed to LPS. Zinc deficiency augmented injury and correlated with decreased levels of lung MT protein after VILI, raising the possibility that zinc deficiency in humans may be an important risk factor compromising the lung's capacity to tolerate MV. Moreover, we demonstrated that VILI produces plasma zinc deficiency in mice with normal zinc, suggesting a potentially novel mechanism underlying lung injury. Supporting clinical relevance, we observed lower circulating plasma zinc in ICU patients who developed ARDS, compared with control subjects, as well as critically ill subjects with sepsis and SIRS. Our findings offer a strong rationale for expanding efforts to protect the lung. Basing interventions on endogenous, dietdependent, stretch-adaptive responses offers an attractive new rationale for therapeutics.

Zinc is an essential micronutrient, the tissue level and distribution of which are controlled through regulatory mechanisms $(33,38,71)$, and moderate zinc deficiency from low dietary intake remains prevalent $(42,66)$. Only $51 \%$ of the population aged $51-70$ were found to have adequate zinc, dipping to $43 \%$ in the $70+$ age group (66). Zinc plasma levels and tissue distribution are also altered in the acute-phase response (72), and lower zinc plasma concentrations have been noted across a variety of critical illnesses, although it is not clear that the implications of low plasma zinc are similar in chronic diet-induced insufficiency and redistributive changes associated with illness (33). Our findings show that circulating plasma zinc levels are reduced in critically ill subjects who develop ARDS versus control subjects, as well as critically ill subjects with sepsis and SIRS, supporting a role for zinc levels in defining the lung's injury response to MV.

Our mouse studies demonstrate that dietary zinc deficiency primes the lung for injury from MV. Previous findings linked zinc deficiency to immune cell dysfunction, and to increased susceptibility to airway infections $(45,73)$. In murine polymicrobial sepsis (67), zinc deficiency produced increased inflammation similar to that evoked here by MV. Our results extend the relevance of zinc deficiency to sterile lung injury evoked through a stretch-mediated mechanism. While another group reported that zinc deficiency exacerbates VILI in rats (74), they observed that injury was mediated through modulation of inflammation rather than through mechanotransduction, which is a potentially novel observation in our study. We observed increased BAL protein and inflammatory cell infiltrates in zinc-deficient mechanically ventilated mice. Clearly, perturbations in zinc dietary status can evoke complex and interrelated effects on lung physiology 
A

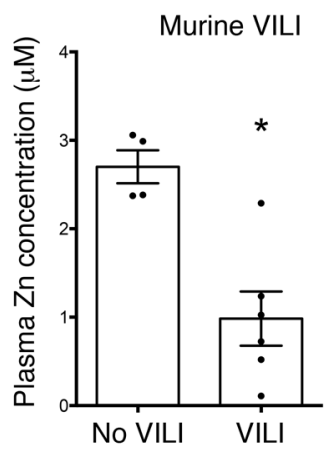

Figure 7. Zinc levels are reduced in mice subjected to ventilator-induced lung injury (VILI) and in human plasma collected from acute respiratory distress syndrome (ARDS) subjects. (A) Plasma zinc levels were measured in mice at baseline and after 8 hours of VILI ( $15 \mathrm{ml} / \mathrm{kg})(n=4-6 /$ group $)$ using a commercially available colorimetric zinc assay kit. ${ }^{*} P<0.01$ by 2 -tailed Mann-Whitney $U$ test; data presented as mean \pm SEM. (B) Plasma zinc levels were measured from intensive care unit (ICU) subjects at admission who went on to develop $\operatorname{ARDS}(n=21$, all subjects mechanically ventilated), sepsis ( $n=$ 62), systemic inflammatory response syndrome (SIRS, $n=26$ ), and control subjects ( $n=3$ ICU controls and 4 healthy subjects). Blood was collected in EDTA-free tubes, and zinc plasma levels were assayed using a commercially available colorimetric zinc assay kit. ${ }^{*} P<0.001$ versus control by 1 -way ANOVA with Newman-Keuls post-hoc test; data presented as mean \pm SEM.

and inflammation. Interestingly, these effects were not seen in non-mechanically ventilated animals, but instead were augmented responses to stretch, demonstrating that lung-specific manifestations of zinc deficiency are evident only after an initiating event such as VILI.

Our study began with the observation of prominent upregulation of MT expression by stretch in vitro and high-Vt ventilation in vivo. MTs are endowed with a broad set of protective functions, including antioxidant and antiapoptotic effects $(22-28,75,76)$. Moreover, genetic deficiency in MTs is known to worsen lung injury in LPS- (27) and nickel-exposure (28) models, although ours is the first to our knowledge to link MT with protection from VILI. While our results confirm that absence of MT expression has no effect on baseline lung function, they demonstrate that inability to upregulate MT after stretch amplifies deleterious effects of VILI. Enhanced lung injury in MT-deficient animals may result directly from the loss of cellprotective functions, or may reflect impairments in cellular zinc levels or zinc buffering capacity, as zinc itself has antioxidant functions $(32,34-36)$ and also plays contrasting injurious or cytoprotective roles in cell death pathways depending upon intracellular concentration $(34,77)$. Previous work showed that lung stretch induces excessive reactive oxygen and nitrogen species generation in mechanically ventilated lungs, contributing to lung injury $(57,68,78-82)$; reactive oxygen and nitrogen species have been previously linked to regulation of MT expression and NO has been linked to S-nitrosation of MT resulting in increases in labile zinc (83). Alterations in intracellular zinc levels and MT expression may reflect a homeostatic program that normally limits stretch-induced injury.

Taken together, these results support the emerging concept that lung stretch promotes endogenous protection (84) in addition to better-recognized injury responses. The possibility that beneficial responses lie downstream of pathways otherwise associated with lung injury emphasizes the need to design interventions that selectively enhance lung protection in MV. Our findings suggest that the zinc/MT system represents one appealing target for selective amplification of lung protection. Based on mounting evidence of associations between critically ill populations and perturbations in zinc levels, the rationale for testing interventions aimed at this putative protective mechanism appears compelling.

\section{Methods}

Reagents. TPEN [N,N,N',N'-tetrakis (2-pyridylmethyl)ethylenediamine], dissolved in ethanol, and zinc chloride were from Sigma-Aldrich.

Cell culture and cell stretch studies. Human juvenile (5-year-old donor) lung fibroblasts CCL-151 (ATCC), human fetal lung fibroblasts CCL-153 (ATCC), A549 lung adenocarcinoma (ATCC), and 16HBE14obronchial epithelial cells (gift from Dieter Gruenert, UC San Francisco, San Francisco, California, USA) were used. Tonic biaxial deformation of cells was achieved with a previously described stretch device (50). Please see supplement for additional details.

MTF1 reporter assay. MTF1 DNA-binding activity changes upon treatment were assessed with the luciferase-based assay Cignal MTF1 Reporter (QIAGEN, CCS-5033L) as described by the manufacturer.

$D N A$ microarray analysis, $R N A$ isolation, reverse transcription and $q P C R, R N A$ interference. The microarray data have been deposited into NCBI's Gene Expression Omnibus (GEO GSE80161). Please also see supplemental methods.

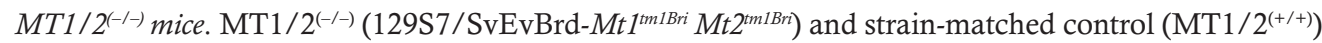
male mice (129S1/SvImJ) were used (Jackson Laboratory, 6 weeks old).

Zinc deficiency and measurement of zinc. Under an IACUC-approved protocol (67), WT C57BL/6 male mice (Jackson Laboratory, 6 weeks old) were subjected to a zinc-depleted diet (Harlan Teklad, TD85419; 
1 ppm Zn) along with animals on a control matched diet (Standard chow; 50 ppm Zn) for 3 weeks. At termination of the experiments (see below), blood was collected from the mice via right ventricle puncture and plasma isolated and stored. Zinc plasma levels were measured using a commercially available assay (QuantiChrom Zinc Assay Kit, BioAssay Systems).

Mouse models of VILI and LPS+VILI: assessment of lung injury. Under IACUC-approved protocols, $\mathrm{MT} 1 / 2^{(--)}$mice and controls were subjected to VILI on the mouse Flexivent ventilator using a Vt of $24 \mathrm{ml} /$ $\mathrm{kg}$. Zinc-deficient and control mice were subjected to VILI using a Vt of 15 or $24 \mathrm{ml} / \mathrm{kg}$. Hourly measurements of lung physiology were undertaken (68). For dual-lung injury, zinc-deficient and control animals were subjected to $10 \mathrm{mg}$ nebulized endotoxin (LPS, Pseudomonas, Sigma-Aldrich) (68) followed 24 hours later by VILI (Vt $15 \mathrm{ml} / \mathrm{kg}$ ). BAL fluid was then collected; lung tissue was harvested and stored for RNA analysis or for immunohistochemistry. BAL fluid was collected and analyzed for cell counts, IL-6 levels, and BAL protein levels (68). Lung tissue cytokine measurements were performed (please see supplement). Paraformaldehyde-fixed, paraffin-embedded lung sections were stained with H\&E and for Gr-1 (BD Biosciences, catalog 550291 to detect neutrophils) (68) or MT (Life Technologies, catalog 180133). Western blots were performed on lung tissue protein extracts or cell protein extracts using the anti-MT antibody and anti- $\beta$-actin (Sigma-Aldrich, catalog A5441) as a loading control with a 16\% Tricine gel (Thermo Fisher) as previously described (85).

Human plasma sample analysis. Banked plasma samples were analyzed from patients enrolled in our IRB-approved Registry of Critical Illness $(69,70)$. Zinc levels were measured as described above. Please see supplemental materials for additional details.

Statistics. Data were plotted and analyzed using Prism (GraphPad) or MS Excel software. For comparisons between 2 groups, a Student's 2-tailed $t$ test was used for parametric data and a Mann-Whitney $U$ test was used for nonparametric data. For comparisons between multiple groups, a 1-way or 2-way ANOVA was performed depending upon the number of experimental groups. A $P$ value less than 0.05 was considered statistically significant. Please see supplemental materials for additional details regarding human subject analyses.

Study approval. Animal studies were carried out under approved IACUC protocols by the Harvard University Standing Committee on Animals. Plasma samples and clinical data from human subjects were collected with written consent under our Partners Healthcare IRB-approved Registry of Critical Illness.

\section{Author contributions}

FB, MPV, JAE, ATK, CI, AJA, DBB, CQ, DA, JG, KMC, MR, LS, SH, DJT, and RMB acquired, analyzed, and interpreted data. JAE, DJT, and RMB conceived and designed the study. FB, MPV, JAE, ATK, CQ, DA, DJT, and RMB drafted the manuscript. MPV, JAE, DJT, and RMB critically revised the manuscript for intellectual content. All authors approved the final version of the manuscript and agree to be accountable for all aspects of the study.

\section{Acknowledgments}

This work was supported in part by NIH grants HL082856, HL091124, HL088028, GM102695, and HL091957. Microarray studies were performed by the Molecular Genetics Core Facility at Children's Hospital Boston, supported by NIH grants P50-NS40828 and P30-HD18655.

See Supplemental Acknowledgments for MICU Registry Consortium details.

Address correspondence to: Rebecca M. Baron, Pulmonary and Critical Care Medicine, Brigham and Women's Hospital, 75 Francis Street, Boston, Massachusetts 02115, USA. Phone: 617.525.6642; E-mail: rbaron@partners.org.

1. Rubenfeld GD, et al. Incidence and outcomes of acute lung injury. N Engl J Med. 2005;353(16):1685-1693.

2. ARDS Definition Task Force, et al. Acute respiratory distress syndrome: the Berlin Definition. JAMA. 2012;307(23):2526-2533.

3. Matthay MA, Ware LB, Zimmerman GA. The acute respiratory distress syndrome. J Clin Invest. 2012;122(8):2731-2740.

4. Oeckler RA, Hubmayr RD. Ventilator-associated lung injury: a search for better therapeutic targets. Eur Respir J. 2007;30(6):1216-1226.

5. International consensus conferences in intensive care medicine: Ventilator-associated Lung Injury in ARDS. This official confer- 
ence report was cosponsored by the American Thoracic Society, The European Society of Intensive Care Medicine, and The Societé de Réanimation de Langue Française, and was approved by the ATS Board of Directors, July 1999. Am J Respir Crit Care Med. 1999;160(6):2118-2124.

6. Pinhu L, Whitehead T, Evans T, Griffiths M. Ventilator-associated lung injury. Lancet. 2003;361(9354):332-340.

7. Acute Respiratory Distress Syndrome Network, et al. Ventilation with lower tidal volumes as compared with traditional tidal volumes for acute lung injury and the acute respiratory distress syndrome. N Engl J Med. 2000;342(18):1301-1308.

8. Ranieri VM, et al. Effect of mechanical ventilation on inflammatory mediators in patients with acute respiratory distress syndrome: a randomized controlled trial. JAMA. 1999;282(1):54-61.

9. Amato $\mathrm{MB}$, et al. Beneficial effects of the "open lung approach" with low distending pressures in acute respiratory distress syndrome. A prospective randomized study on mechanical ventilation. Am J Respir Crit Care Med. 1995;152(6 Pt 1):1835-1846.

10. Villar J, et al. The ALIEN study: incidence and outcome of acute respiratory distress syndrome in the era of lung protective ventilation. Intensive Care Med. 2011;37(12):1932-1941.

11. Uhlig S, Uhlig U. Pharmacological interventions in ventilator-induced lung injury. Trends Pharmacol Sci. 2004;25(11):592-600

12. Plataki M, Hubmayr RD. The physical basis of ventilator-induced lung injury. Expert Rev Respir Med. 2010;4(3):373-385.

13. Matthay MA, et al. Ventilator-induced lung injury: in vivo and in vitro mechanisms. Am J Physiol Lung Cell Mol Physiol. 2002;283(4):L678-L682.

14. Tremblay LN, Slutsky AS. Ventilator-induced injury: from barotrauma to biotrauma. Proc Assoc Am Physicians. 1998;110(6):482-488.

15. Le A, et al. Alveolar cell apoptosis is dependent on p38 MAP kinase-mediated activation of xanthine oxidoreductase in ventilator-induced lung injury. J Appl Physiol. 2008;105(4):1282-1290.

16. Li LF, Yu L, Quinn DA. Ventilation-induced neutrophil infiltration depends on c-Jun N-terminal kinase. Am J Respir Crit Care Med. 2004;169(4):518-524.

17. Dolinay T, et al. Mitogen-activated protein kinases regulate susceptibility to ventilator-induced lung injury. PLoS One. 2008;3(2):e1601.

18. Hammerschmidt S, Kuhn H, Gessner C, Seyfarth HJ, Wirtz H. Stretch-induced alveolar type II cell apoptosis: role of endogenous bradykinin and PI3K-Akt signaling. Am J Respir Cell Mol Biol. 2007;37(6):699-705

19. Lionetti V, et al. Lack of phosphoinositide 3-kinase-gamma attenuates ventilator-induced lung injury. Crit Care Med. 2006;34(1):134-141.

20. Miyahara T, Hamanaka K, Weber DS, Drake DA, Anghelescu M, Parker JC. Phosphoinositide 3-kinase, Src, and Akt modulate acute ventilation-induced vascular permeability increases in mouse lungs. Am J Physiol Lung Cell Mol Physiol. 2007;293(1):L11-L21.

21. Meyer NJ, et al. GADD45a is a novel candidate gene in inflammatory lung injury via influences on Akt signaling. FASEB J. 2009;23(5):1325-1337.

22. Maret W. Metallothionein redox biology in the cytoprotective and cytotoxic functions of zinc. Exp Gerontol. 2008;43(5):363-369.

23. Palmiter RD. The elusive function of metallothioneins. Proc Natl Acad Sci USA. 1998;95(15):8428-8430.

24. Fabisiak JP, Borisenko GG, Liu SX, Tyurin VA, Pitt BR, Kagan VE. Redox sensor function of metallothioneins. Meth Enzymol. 2002;353:268-281.

25. Inoue K, Takano H, Shimada A, Satoh M. Metallothionein as an anti-inflammatory mediator. Mediators Inflamm. 2009;2009:101659.

26. Kondo Y, Rusnak JM, Hoyt DG, Settineri CE, Pitt BR, Lazo JS. Enhanced apoptosis in metallothionein null cells. Mol Pharmacol. 1997;52(2):195-201.

27. Takano H, et al. Protective role of metallothionein in acute lung injury induced by bacterial endotoxin. Thorax. 2004;59(12):1057-1062.

28. Wesselkamper SC, et al. The role of metallothionein in the pathogenesis of acute lung injury. Am J Respir Cell Mol Biol. 2006;34(1):73-82

29. Bao S, Knoell DL. Zinc modulates cytokine-induced lung epithelial cell barrier permeability. Am J Physiol Lung Cell Mol Physiol. 2006;291(6):L1132-L1141.

30. Bao S, Knoell DL. Zinc modulates airway epithelium susceptibility to death receptor-mediated apoptosis. Am J Physiol Lung Cell Mol Physiol. 2006;290(3):L433-L441.

31. Besecker B, Bao S, Bohacova B, Papp A, Sadee W, Knoell DL. The human zinc transporter SLC39A8 (Zip8) is critical in zincmediated cytoprotection in lung epithelia. Am J Physiol Lung Cell Mol Physiol. 2008;294(6):L1127-L1136.

32. Bray TM, Bettger WJ. The physiological role of zinc as an antioxidant. Free Radic Biol Med. 1990;8(3):281-291.

33. King JC. Zinc: an essential but elusive nutrient. Am J Clin Nutr. 2011;94(2):679S-684S.

34. Plum LM, Rink L, Haase H. The essential toxin: impact of zinc on human health. Int J Environ Res Public Health. 2010;7(4):1342-1365.

35. Powell SR. The antioxidant properties of zinc. J Nutr. 2000;130(5S Suppl):1447S-1454S.

36. Prasad AS, Bao B, Beck FW, Kucuk O, Sarkar FH. Antioxidant effect of zinc in humans. Free Radic Biol Med. 2004;37(8):1182-1190.

37. Zhou Z, Sun X, Lambert JC, Saari JT, Kang YJ. Metallothionein-independent zinc protection from alcoholic liver injury. Am J Pathol. 2002;160(6):2267-2274.

38. Cousins RJ, Liuzzi JP, Lichten LA. Mammalian zinc transport, trafficking, and signals. J Biol Chem. 2006;281(34):24085-24089.

39. Westin G, Schaffner W. A zinc-responsive factor interacts with a metal-regulated enhancer element (MRE) of the mouse metallothionein-I gene. EMBO J. 1988;7(12):3763-3770.

40. Haase H, Overbeck S, Rink L. Zinc supplementation for the treatment or prevention of disease: current status and future perspectives. Exp Gerontol. 2008;43(5):394-408.

41. Haase H, Rink L. Functional significance of zinc-related signaling pathways in immune cells. Annu Rev Nutr. 2009;29:133-152.

42. Walsh CT, Sandstead HH, Prasad AS, Newberne PM, Fraker PJ. Zinc: health effects and research priorities for the 1990s. Environ Health Perspect. 1994;102 Suppl 2:5-46.

43. Goode HF, Penn ND, Kelleher J, Walker BE. Evidence of cellular zinc depletion in hospitalized but not in healthy elderly subjects. Age Ageing. 1991;20(5):345-348. 
44. Schmuck A, Roussel AM, Arnaud J, Ducros V, Favier A, Franco A. Analyzed dietary intakes, plasma concentrations of zinc, copper, and selenium, and related antioxidant enzyme activities in hospitalized elderly women. J Am Coll Nutr. 1996;15(5):462-468.

45. Barnett JB, Hamer DH, Meydani SN. Low zinc status: a new risk factor for pneumonia in the elderly? Nutr Rev. 2010;68(1):30-37.

46. Besecker BY, et al. A comparison of zinc metabolism, inflammation, and disease severity in critically ill infected and noninfected adults early after intensive care unit admission. Am J Clin Nutr. 2011;93(6):1356-1364.

47. Duncan A, Dean P, Simm M, O'Reilly DS, Kinsella J. Zinc supplementation in intensive care: results of a UK survey. J Crit Care. 2012;27(1):102.e1-102.e6.

48. Linko R, et al. Serum zinc in critically ill adult patients with acute respiratory failure. Acta Anaesthesiol Scand. 2011;55(5):615-621.

49. Cander B, Dundar ZD, Gul M, Girisgin S. Prognostic value of serum zinc levels in critically ill patients. J Crit Care. 2011;26(1):42-46.

50. Boudreault F, Tschumperlin DJ. Stretch-induced mitogen-activated protein kinase activation in lung fibroblasts is independent of receptor tyrosine kinases. Am J Respir Cell Mol Biol. 2010;43(1):64-73.

51. Hammerschmidt S, Kuhn H, Grasenack T, Gessner C, Wirtz H. Apoptosis and necrosis induced by cyclic mechanical stretching in alveolar type II cells. Am J Respir Cell Mol Biol. 2004;30(3):396-402.

52. Tschumperlin DJ, Margulies SS. Equibiaxial deformation-induced injury of alveolar epithelial cells in vitro. Am J Physiol. 1998;275(6 Pt 1):L1173-L1183.

53. Perlman CE, Bhattacharya J. Alveolar expansion imaged by optical sectioning microscopy. J Appl Physiol. 2007;103(3):1037-1044

54. Tschumperlin DJ, Margulies SS. Alveolar epithelial surface area-volume relationship in isolated rat lungs. J Appl Physiol. 1999;86(6):2026-2033.

55. Ma SF, et al. Bioinformatic identification of novel early stress response genes in rodent models of lung injury. Am J Physiol Lung Cell Mol Physiol. 2005;289(3):L468-L477.

56. Simon BA, et al. Microarray analysis of regional cellular responses to local mechanical stress in acute lung injury. Am J Physiol Lung Cell Mol Physiol. 2006;291(5):L851-L861.

57. Papaiahgari S, et al. Genetic and pharmacologic evidence links oxidative stress to ventilator-induced lung injury in mice. $A m J$ Respir Crit Care Med. 2007;176(12):1222-1235.

58. Wray C, Mao Y, Pan J, Chandrasena A, Piasta F, Frank JA. Claudin-4 augments alveolar epithelial barrier function and is induced in acute lung injury. Am J Physiol Lung Cell Mol Physiol. 2009;297(2):L219-L227.

59. Masters BA, Kelly EJ, Quaife CJ, Brinster RL, Palmiter RD. Targeted disruption of metallothionein I and II genes increases sensitivity to cadmium. Proc Natl Acad Sci USA. 1994;91(2):584-588

60. Matute-Bello G, et al. An official American Thoracic Society workshop report: features and measurements of experimental acute lung injury in animals. Am J Respir Cell Mol Biol. 2011;44(5):725-738.

61. Heuchel R, Radtke F, Georgiev O, Stark G, Aguet M, Schaffner W. The transcription factor MTF-1 is essential for basal and heavy metal-induced metallothionein gene expression. EMBO J. 1994;13(12):2870-2875.

62. Palmiter RD, Sandgren EP, Koeller DM, Brinster RL. Distal regulatory elements from the mouse metallothionein locus stimulate gene expression in transgenic mice. Mol Cell Biol. 1993;13(9):5266-5275.

63. Dalton TP, Bittel D, Andrews GK. Reversible activation of mouse metal response element-binding transcription factor 1 DNA binding involves zinc interaction with the zinc finger domain. Mol Cell Biol. 1997;17(5):2781-2789.

64. Laity JH, Andrews GK. Understanding the mechanisms of zinc-sensing by metal-response element binding transcription factor-1 (MTF-1). Arch Biochem Biophys. 2007;463(2):201-210.

65. Maret W, Li Y. Coordination dynamics of zinc in proteins. Chem Rev. 2009;109(10):4682-4707.

66. Briefel RR, Bialostosky K, Kennedy-Stephenson J, McDowell MA, Ervin RB, Wright JD. Zinc intake of the U.S. population: findings from the third National Health and Nutrition Examination Survey, 1988-1994. J Nutr. 2000;130(5S Suppl):1367S-1373S.

67. Knoell DL, et al. Zinc deficiency increases organ damage and mortality in a murine model of polymicrobial sepsis. Crit Care Med. 2009;37(4):1380-1388.

68. Baron RM, et al. Nitric oxide synthase-2 down-regulates surfactant protein-B expression and enhances endotoxin-induced lung injury in mice. FASEB J. 2004;18(11):1276-1278

69. Dolinay T, et al. Inflammasome-regulated cytokines are critical mediators of acute lung injury. Am J Respir Crit Care Med. 2012;185(11):1225-1234.

70. Sun X, et al. MicroRNA-181b regulates NF-кB-mediated vascular inflammation. J Clin Invest. 2012;122(6):1973-1990

71. Cousins RJ, et al. Regulation of zinc metabolism and genomic outcomes. J Nutr. 2003;133(5 Suppl 1):1521S-1526S.

72. Shenkin A. Trace elements and inflammatory response: implications for nutritional support. Nutrition. 1995;11(1 Suppl):100-105

73. Prasad AS, et al. Zinc supplementation decreases incidence of infections in the elderly: effect of zinc on generation of cytokines and oxidative stress. Am J Clin Nutr. 2007;85(3):837-844.

74. Chen X, Bian J, Ge Y. Zinc-deficient diet aggravates ventilation-induced lung injury in rats. J Biomed Res. 2012;26(1):59-65.

75. Dutsch-Wicherek M, Sikora J, Tomaszewska R. The possible biological role of metallothionein in apoptosis. Front Biosci. 2008;13:4029-4038

76. Wang GW, Zhou Z, Klein JB, Kang YJ. Inhibition of hypoxia/reoxygenation-induced apoptosis in metallothionein-overexpressing cardiomyocytes. Am J Physiol Heart Circ Physiol. 2001;280(5):H2292-H2299.

77. Cai L, Li XK, Song Y, Cherian MG. Essentiality, toxicology and chelation therapy of zinc and copper. Curr Med Chem. 2005;12(23):2753-2763.

78. Hammerschmidt $\mathrm{S}$, et al. Influence of tidal volume on pulmonary NO release, tissue lipid peroxidation and surfactant phospholipids. Biochim Biophys Acta. 2003;1639(1):17-26.

79. Peng X, et al. Inducible nitric oxide synthase contributes to ventilator-induced lung injury. Am J Respir Crit Care Med. 2005;172(4):470-479.

80. Broccard AF, Feihl F, Vannay C, Markert M, Hotchkiss J, Schaller MD. Effects of L-NAME and inhaled nitric oxide on ventilator-induced lung injury in isolated, perfused rabbit lungs. Crit Care Med. 2004;32(9):1872-1878.

81. Frank JA, Pittet JF, Lee H, Godzich M, Matthay MA. High tidal volume ventilation induces NOS2 and impairs cAMP- dependent air space fluid clearance. Am J Physiol Lung Cell Mol Physiol. 2003;284(5):L791-L798. 
82. Reddy SP, Hassoun PM, Brower R. Redox imbalance and ventilator-induced lung injury. Antioxid Redox Signal. 2007;9(11):2003-2012.

83. St Croix CM, Leelavaninchkul K, Watkins SC, Kagan VE, Pitt BR. Nitric oxide and zinc homeostasis in acute lung injury. Proc Am Thorac Soc. 2005;2(3):236-242.

84. Akram A, et al. Activating transcription factor 3 confers protection against ventilator-induced lung injury. Am J Respir Crit Care Med. 2010;182(4):489-500.

85. Mizzen CA, Cartel NJ, Yu WH, Fraser PE, McLachlan DR. Sensitive detection of metallothioneins-1, -2 and -3 in tissue homogenates by immunoblotting: a method for enhanced membrane transfer and retention. J Biochem Biophys Methods. 1996;32(2):77-83. 